\title{
EPIDEMIOLOGIA DO TRANSPLANTE DE MEDULA ÓSSEA NO HOSPITAL ARAÚJO JORGE DE 2000 A 2004 EM GOIÂNIA, GOIÁS, BRASIL
}

\author{
Bone marrow transplant epidemiology at Araújo Jorge Hospital \\ from 2000 to 2004 in Goiania, Goiás, Brazil
}

\author{
Ana Carolina Franco Finotti ${ }^{I}$ \\ Claudia Regina Abreue Silva ${ }^{2}$ \\ CésarBariani ${ }^{3}$ \\ Antonio Márcio Teodoro Cordeiro Silva ${ }^{4}$ \\ Cláudio Carlos da Silva ${ }^{5}$ \\ AparecidoDivino da Cruz ${ }^{6}$
}

\section{Resumo}

O transplante de medula óssea (TMO) é uma modalidade terapêutica que se destina ao tratamento de doenças com uso de altas doses de agentes quimioterápicos, associados ou não à radioterapia corporal. A reconstituição hematopoiética do paciente é feita pela infusão de células viáveis da medula óssea ou do sangue periférico. Este artigo apresenta um estudo epidemiológico do TMO no serviço de oncologia do Hospital Araújo Jorge (HAJ), em Goiânia (GO). Foram analisados 106 prontuários, com base nas seguintes variáveis: idade, sexo, tipo de transplante, patologia de base e fonte celular. A média de idade dos pacientes foi de 29,5 anos. De 2000 a 2004 houve aumento significativo na freqüência percentual de transplantes, sendo que o sexo masculino representou $60,4 \%$. As patologias de base mais freqüentes foram o mieloma múltiplo ( 24 casos) e a leucemia mielóide aguda ( 22 casos). Como transplantes, prevaleceram os autólogos (55/106), de grande valia contra o câncer. As células-tronco de sangue periférico $(58,5 \%)$ foram a fonte celular mais utilizada. O sangue é uma fonte cada vez mais freqüente de células-tronco para o transplante. No HAJ, o número de transplantes cresce a cada ano, como pode ser constatado no decorrer deste trabalho. Com isso, a equipe responsável pelos transplantes, em função da experiência adquirida nos mais de cem TMOs realizados, passa a figurar entre as principais da área, no país.

Palavras-chave: Transplante de medula óssea; Células-tronco; Epidemiologia.

\footnotetext{
Departamento de Transplante de Medula Óssea, Hospital Araújo Jorge, Associação de Combate ao Câncer em Goiás. e-mail: finotticarol@hotmail.com

Departamento de Transplante de Medula Óssea, Hospital Araújo Jorge, Associação de Combate ao Câncer em Goiás. e-mail: marciobio@ucg.br Departamento de Transplante de Medula Óssea, Hospital Araújo Jorge, Associação de Combate ao Câncer em Goiás. e-mail: cbariani@uol.com.br Núcleo de Pesquisas Replicon, Departamento de Biologia, Universidade Católica de Goiás. e-mail: marciobio@ucg.br

Núcleo de Pesquisas Replicon, Departamento de Biologia, Universidade Católica de Goiás. e-mail: dasilva@ucg.br

Núcleo de Pesquisas Replicon, Departamento de Biologia, Universidade Católica de Goiás. e-mail: acruz@ucg.br
} 


\section{Abstract}

Bone marrow transplant is a therapeutic modality used in the treatment of some diseases with high dosages of chemotherapic agents associated or not to corporal radiotherapy. Hematopoietic reconstitution is done by the infusion of viable cells in the bone marrow or in peripherical blood of the patients. The aim of this work was an epidemiological study of bone marrow transplantation done in the oncology service of Araújo Jorge Hospital in Goiânia/GO. 106 patient files were analyzed, among the variables: age, sex, transplantation type, and basis pathology and cell type. The mean age of the patients was 29.5 years. From 2000 to 2004 it happened a significative increase in the percentile frequency of the transplants, and males represented $60.4 \%$. The basis pathology more frequents were: multiple mieloma ( 24 cases) and acute myeloid leukemia (22 cases). Predominating the autologous transplants (55/106) and stem cells of peripheral blood $(58.5 \%)$ as the most used cell type. Blood is the most frequent source used for transplantation. Bone marrow autologous transplant has been a great procedure against cancer. It is seen a huge number of transplants each year in HAJ. This data reflects the ripening and acquired experience of the staff responsible for the transplantations. When the obstacles of 100 transplants were overcome, this unity became on of the main services of the country, at transplantation area.

Keywords: Bone marrow transplant (BMT); Stem cells; Epidemiology.

\section{Introdução}

O transplante de medula óssea (TMO) consiste na infusão intravenosa de células progenitoras hematopoéticas com o objetivo de restabelecer a função medular. Este procedimento terapêutico possui propriedades mielo e imunoablativas, sendo utilizado no tratamento de doenças malignas e não-malignas, de natureza congênita ou adquirida (1).

Segundo Lorenzi (2), a porção celular do sangue é composta de eritrócitos, leucócitos e plaquetas. Constituem três linhagens ou séries diferentes de células, que se originam, entretanto, a partir de uma célula-mãe única, denominada célula pluripotente. Esta célula pluripotente tem a capacidade de transdiferenciação, ou seja, de se adaptar e se desenvolver em ambientes diferentes do seu ambiente de origem.

A hematopoese é um sistema altamente organizado responsável pela produção das células sanguíneas. O controle da proliferação, diferenciação e maturação destas células é feito por meio de uma complexa interação molecular das células com o microambiente da medula óssea. Em indivíduos adultos, a hematopoese se compartimentaliza na medula óssea de ossos chatos, gerando eritrócitos e leucócitos. Em termos quantitativos, a hematopoese apresenta a produção celular alta, em torno de $10^{12} \mathrm{de}$ células sanguíneas/dia/kg, em adultos (3).

Segundo Abbas et al. (4), todos os elementos do sangue originam-se de uma célula indiferenciada comum, que se torna comprometida a diferenciar-se em linhagens particulares (eritróide, megacariocítica, granulocítica, monocítica e linfocítica). A proliferação e maturação das células precursoras na medula óssea são estimuladas por citocinas. Muitas destas citocinas são também chamadas "fatores estimulantes de colônias", porque são avaliadas pela sua capacidade de estimular o crescimento e o desenvolvimento da várias colônias de leucócitos, a partir das células da medula.

O transplante de medula óssea (TMO) é um consagrado tratamento de várias doenças oncológicas, hematológicas, imunológicas e genéticas (5). Essa modalidade terapêutica visa a enxertar a célula progenitora hematopoética $(\mathrm{CPH})$, procurando corrigir um defeito quantitativo ou qualitativo da medula óssea, assim como reconstruir o órgão hematopoético lesado por um mecanismo auto-imune, tóxico ou em decorrência de proliferação celular neoplásica (6).

No momento atual, tem-se discutido a necessidade de modificar a nomenclatura do procedimento do transplante, já que a medula óssea não é mais a única fonte utilizada para obtenção de células progenitoras hematopoéticas (7).

A nomenclatura mais adequada e atual é Transplante de Células-Tronco Hematopoéticas (TCTH), com as seguintes fontes de células progenitoras: células de medula óssea, células-tronco do sangue periférico, células de sangue de cordão umbilical, células de fígado fetal, células cultivadas e células geneticamente modificadas (8). O fundamento lógico para o transplante de células-tronco está baseado no fato de que todas as células do sangue (como glóbulos vermelhos, fagócitos e plaquetas, por exemplo) e as células de imunidade (linfócitos) nascem das células-tronco que estão presentes na medula (9). 
Assim, o objetivo do presente trabalho foi desenvolver um estudo epidemiológico visando a compreender as características e a dinâmica dos transplantes de medula óssea no Serviço de Oncologia do Hospital Araújo Jorge, em Goiânia/GO, no período de 2000 a 2004.

\section{Material e métodos}

A presente análise epidemiológica corresponde a um estudo retrospectivo de pacientes submetidos ao transplante de medula óssea (TMO) no Hospital Araújo Jorge (HAJ), no período de junho/2000 a novembro/2004. Para o cadastro dos pacientes, utilizou-se uma ficha padronizada para a coleta de dados.

Foram analisados 106 prontuários do arquivo médico do HAJ, evidenciando as seguintes variáveis: idade, sexo, tipo de transplante, patologia de base, fonte celular, tipagem sanguínea, volume de sangue coletado, volume de sangue infundido, quantidade de leucócitos, quantidade de linfomonos e quantidade de células CD34+.

Os dados dos respectivos pacientes foram tabulados em planilhas eletrônicas, apoiados por uma análise descritiva, utilizando, para tal, de média, freqüência percentual e desvio-padrão. Para os cálculos estatísticos e confecção dos gráficos, usou-se o software Microsoft Excel $^{\mathbb{}}$ (Microsoft Corporation, EUA).

\section{Resultados}

No período estudado, realizaram-se 106 transplantes de medula óssea no Hospital Araújo Jorge, em Goiânia (GO). Os pacientes transplantados apresentavam uma média de idade de aproximadamente 29 anos (Tabela 1).

Tabela 1 - Número de pacientes por sexo e média de idades, com desvio-padrão e variações

\begin{tabular}{lcccccc}
\hline Sexo & $\begin{array}{c}\text { Número } \\
\text { de Casos }\end{array}$ & $\boldsymbol{f ( \% )}$ & $\begin{array}{c}\text { Média das } \\
\text { Idades } \\
\text { (anos) }\end{array}$ & $\begin{array}{c}\text { DP } \\
\text { (anos) }\end{array}$ & $\begin{array}{c}\text { Menor } \\
\text { (anos) }\end{array}$ & $\begin{array}{c}\text { Maior } \\
\text { (anos) }\end{array}$ \\
\hline Masculino & 64 & 60,4 & 30,6 & 17,7 & 2 & 72 \\
Feminino & 42 & 39,6 & 27,9 & 17,3 & 0,4 & 60 \\
Ambos & 106 & 100,0 & 29,5 & 17,5 & 0,4 & 72 \\
\hline
\end{tabular}

Em 2000, foi realizado um total de seis transplantes, perfazendo 5,7\% dos casos. Em 2001, 11 pacientes foram submetidos ao transplante $(10,4 \%)$. Em 2002, efetuou-se um total de $20,8 \%$ dos transplantes (22/106). Já em 2003, 36 pacientes (34\%) receberam o transplante. E, finalmente, no corrente ano, foi realizado um total de 31 transplantes até 16 de novembro de 2004 (29,2\%) (Figura 1). 


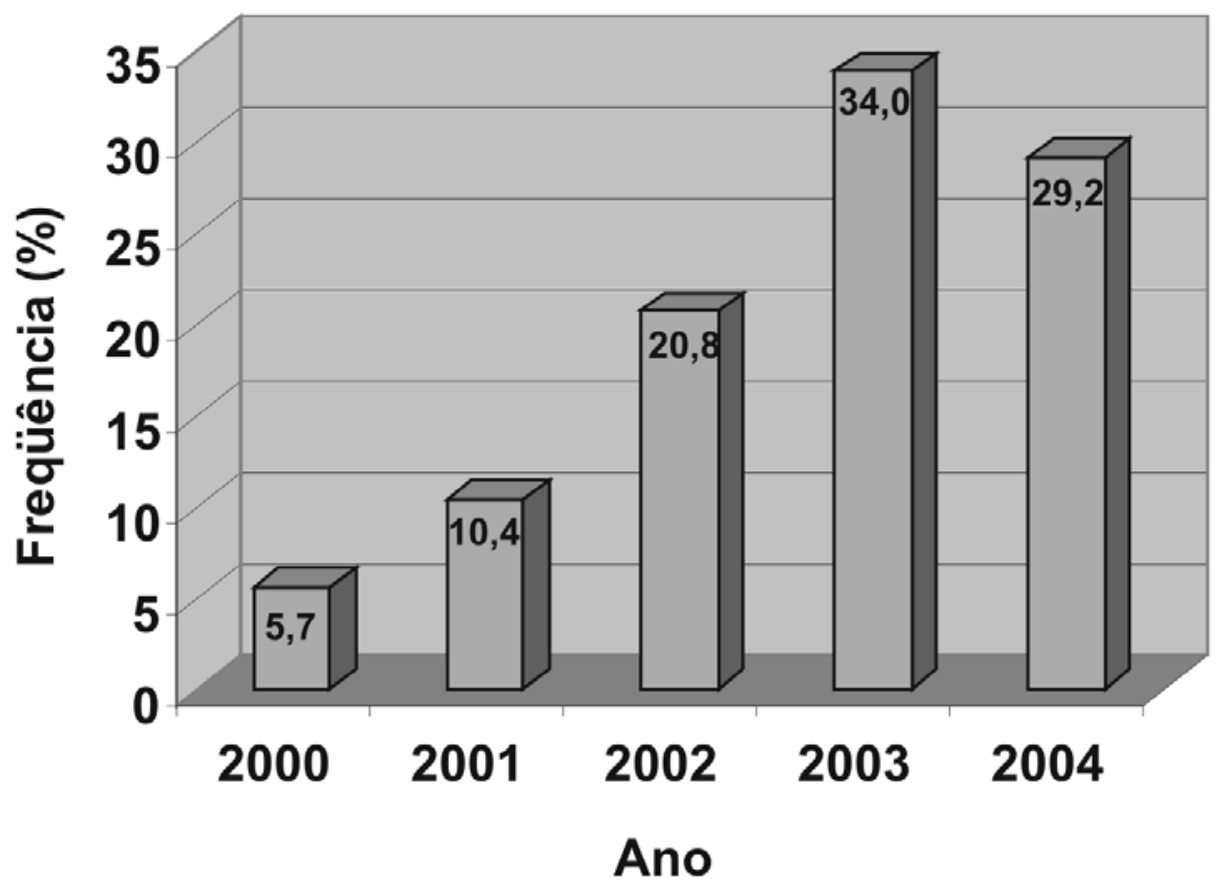

Figura 1 - Freqüência percentual de transplante de medula óssea no HAJ de 2000 a 2004

Em relação às freqüências percentuais de pacientes transplantados por sexo, obtêm-se os seguintes resultados: 64 (60,4\%) pacientes do sexo masculino e $42(39,6 \%)$ pacientes do sexo feminino (Figura 2).

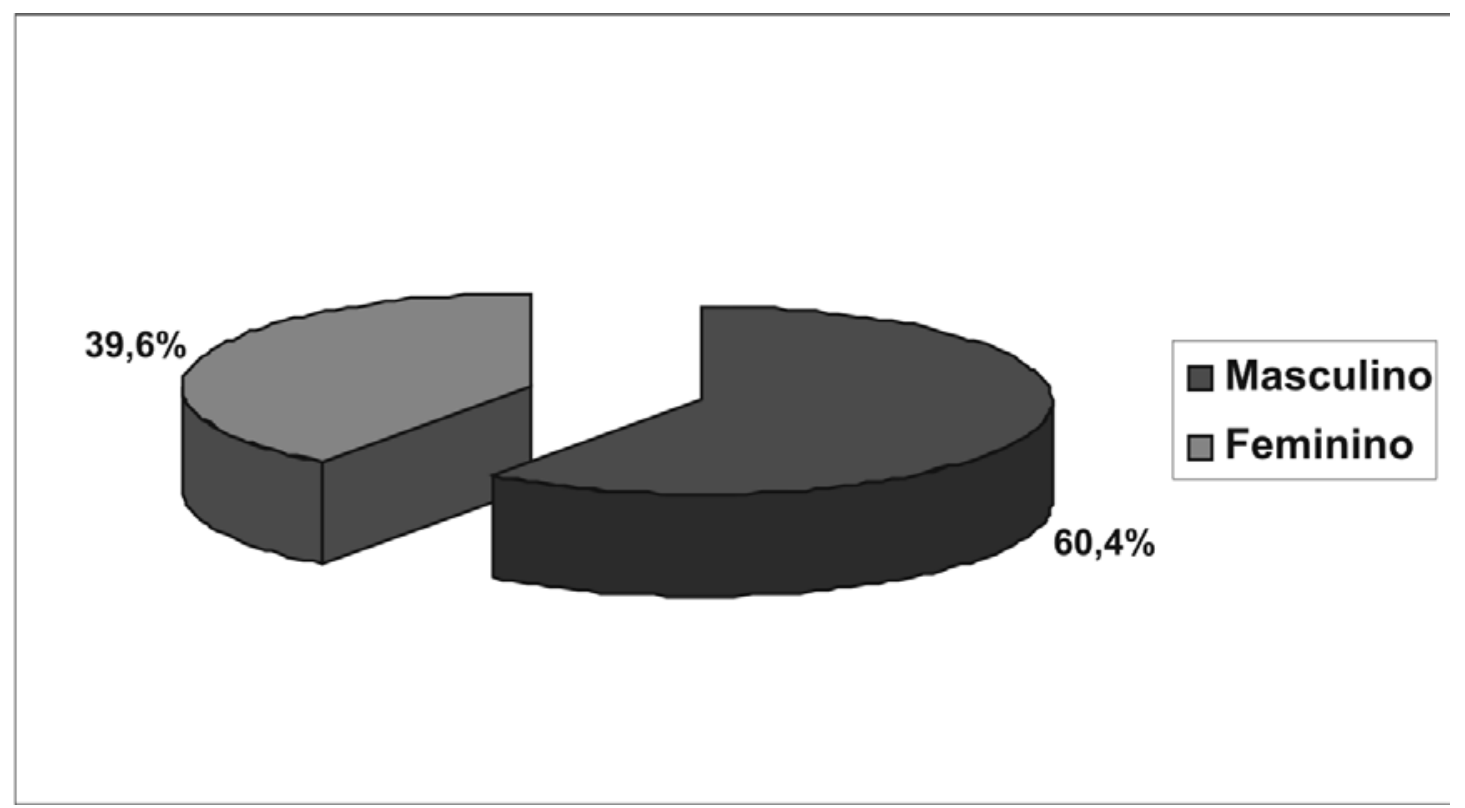

Figura 2 - Freqüênciapercentual depacientestransplantados por sexonoHAJde 2000 a 2004 


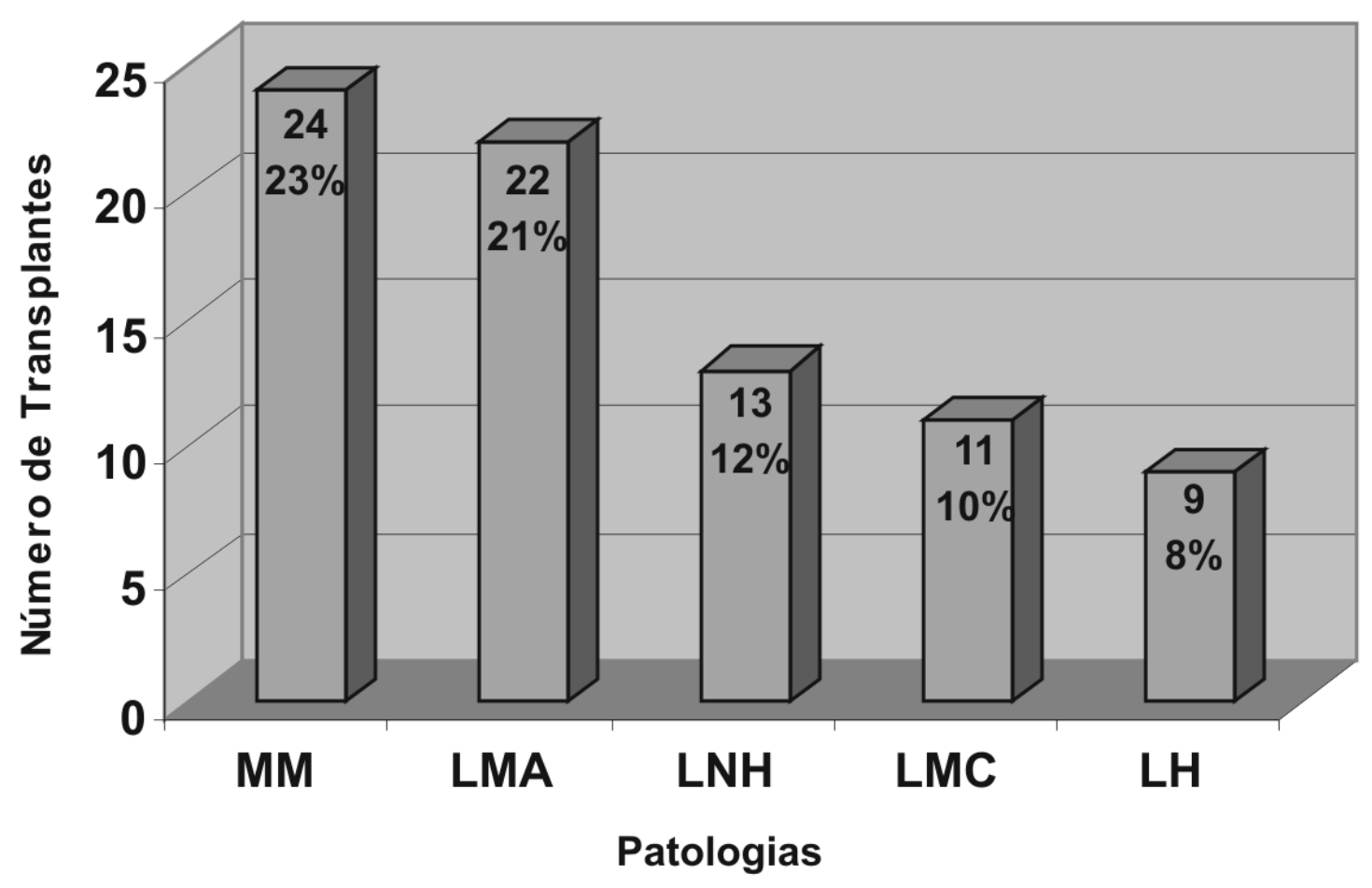

Figura 3 - Número de casos e freqüência percentual das patologias mais incidentes em indivíduos transplantados no HAJ de 2000 a 2004

A Figura 3 sumariza as principais doenças primárias dos pacientes submetidos ao TMO. O mieloma múltiplo (MM) prevaleceu numa incidência de $23 \%$ dos casos. A leucemia mielóide aguda (LMA) correspondeu a $21 \%$ dos casos. As outras patologias mais incidentes foram: linfoma não-Hodking $(\mathrm{LNH})$ (12\%), leucemia mielóide crônica (LMC), em 10\% dos pacientes e, finalmente, o linfoma de Hodking (LH), em $8 \%$ dos casos.
Nos pacientes submetidos ao transplante alogênico, prevaleceram as leucemias mielóides agudas (13 casos); nos transplantes autólogos (51 transplantes alogênicos e 55 transplantes autólogos), predominaram os mielomas múltiplos (22 casos). Como se pode constatar, há equilíbrio entre os tipos de transplantes realizados no HAJ (Tabela 2). 
Tabela 2 - Doenças de base dos pacientes submetidos ao TMO etipo de transplante

\begin{tabular}{lc}
\hline Patologia & N \\
\hline Alogênico & $\mathbf{5 1}$ \\
Leucemia Mielóide Aguda & 13 \\
Leucemia Mielóide Crônica & 11 \\
Anemia Mielóide & 5 \\
Leucemia Linfóide Aguda & 5 \\
Síndrome Mielodisplásica & 3 \\
Anemia Aplástica & 2 \\
Câncer de Testículo & 2 \\
Linfoma Hodking & 2 \\
Linfoma não-Hodking & 2 \\
Mieloma Múltiplo & 2 \\
Linfoma Manto Tipo B & 1 \\
Linfoma de Células T & 1 \\
Leucemia Mielóide Crônica + Anemia Refratária & 1 \\
Mielodisplasia & 1 \\
Autólogo & $\mathbf{5 5}$ \\
Mieloma Múltiplo & 22 \\
Linfoma não-Hodking & 11 \\
Leucemia Mielóide Crônica & 9 \\
Linfoma Hodking & 1 \\
Câncer de Testículo & 1 \\
Esclerose Múltipla & 1 \\
Linfoma Manto Tipo I & 1 \\
Leucemia Linfóide Aguda & 1 \\
LLH & 1 \\
Macroglobulina Waldstrons & 1 \\
\hline & 1 \\
\hline
\end{tabular}


Em relação ao tipo de fonte de células utilizadas no transplante, verifica-se uma preferência pela utilização das células progenitoras de sangue periférico (CPSP), em um percentual de 58,5\% (62/106) dos casos, seguido pela da medula óssea (MO), em 34\% (36/106). A associação dessas fontes (MO+CPSP) ocorreu em apenas 7\% (8/ 106) dos casos (Figura 4).

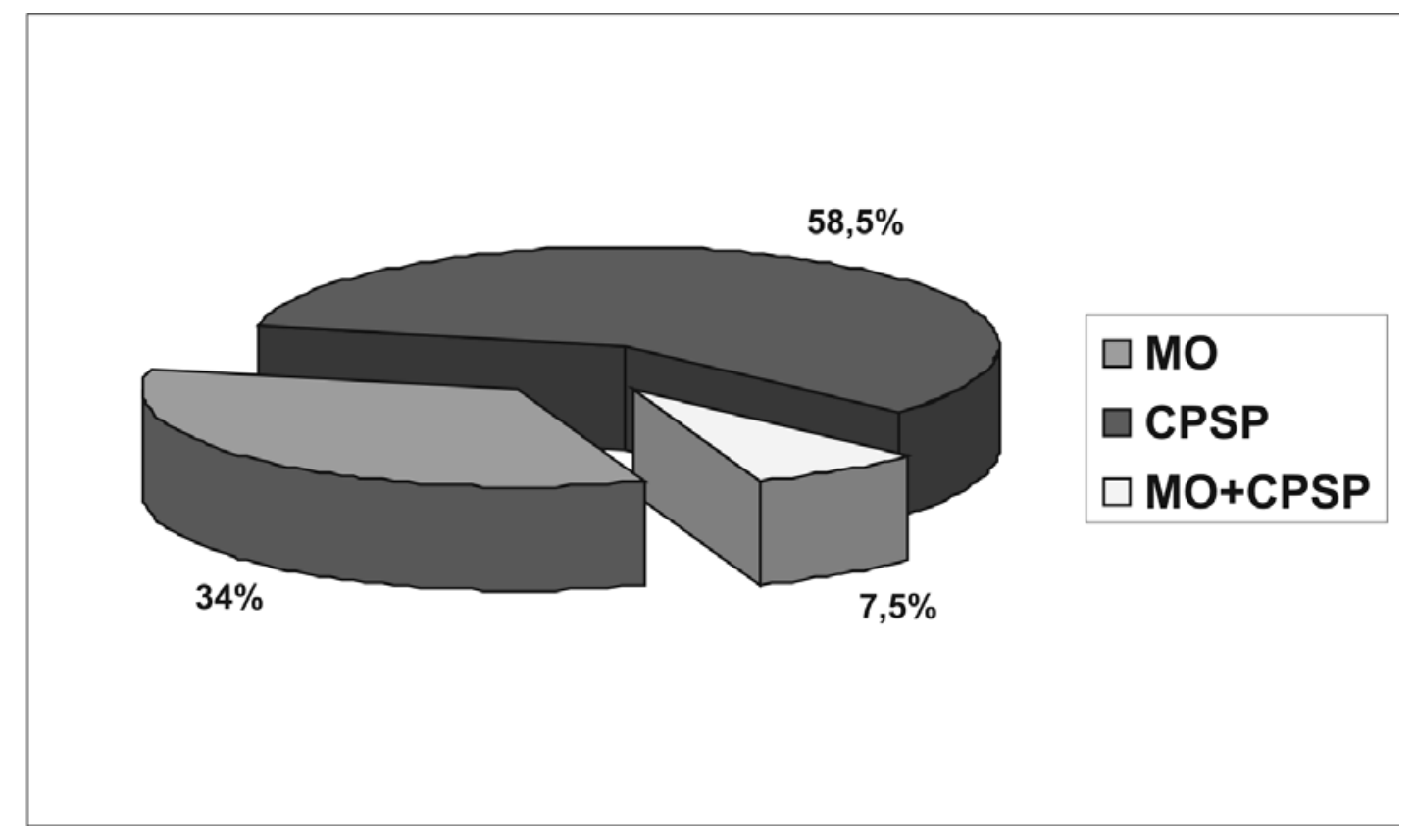

\section{Figura 4 - Freqüência percentual de fonte de células utilizada nos transplantes no HAJ de 2000 a 2004}

\section{Discussão}

As considerações aqui feitas apresentam as limitações de um estudo retrospectivo. Convém ressaltar, entretanto, que não há nenhum trabalho publicado, até o presente momento, com o objetivo de avaliar de maneira global os resultados do TMO no Hospital Araújo Jorge. Ao romper a barreira de cem transplantes, essa unidade passa, indubitavelmente, a figurar entre os principais serviços da área no país.

Na análise do parâmetro "idade do paciente", os resultados encontrados (média de idade de 29 anos) estão em concordância com a literatura, com exceção do transplante realizado em um paciente de 72 anos, que ultrapassa o limite máximo adotado pela maior parte dos serviços, que é de 65 anos (10). A idade do paciente é um fator importante tanto para inclusão como para evolução do paciente após o TMO, entretanto a avaliação clínica pode ser um item prevalente em decisões que envolvam casos que excedam os limites padronizados (11).
O sexo dos indivíduos transplantados não pareceu estar relacionado às doenças de base apresentadas pelos pacientes aqui analisados, apesar da freqüência percentual de homens $(60,4 \%)$ ser consideravelmente maior que a de mulheres $(39,6 \%)$.

Quanto às células-tronco para transplante, o sangue é a fonte mais freqüente. As células-tronco do sistema hematopoiético, encarregadas do repovoamento medular, podem ser obtidas basicamente de duas fontes: das células diretamente aspiradas da medula óssea ou das células-tronco periféricas (stem cell), mobilizadas do compartimento medular para o sangue periférico (12). Essas células, por sua vez, são detectadas em baixos níveis no sangue periférico, sendo, portanto, necessária a mobilização das células da medula óssea para o sangue periférico. A preferência por esse tipo celular deve-se a uma maior contagem de células nucleadas CD $34+\times 10^{6} / \mathrm{Kg}$ por peso do paciente, sendo geralmente uma média de $7 \times 10^{6} / \mathrm{kg}$, em correlação com a medula óssea $\left(2,8 \times 10^{6} / \mathrm{kg}\right)$. Como se constatou neste trabalho, a escolha de células de sangue periférico (CPSP) tem 
sido a principal fonte celular utilizada nos cinco anos de existência do serviço do HAJ, perfazendo um total de 58,5\%. Esses resultados estão de acordo com a literatura revisada, pois as células CD34+encontradas no sangue periférico são fenotipicamente mais imaturas e possuem maior plasticidade fenotípica, ou seja, maior capacidade de transdiferenciação e adaptação a microambientes de diferentes tecidos do originário. Assim, a reconstituição hematopoiética após a aplasia medular é mais rápida e apresenta menor incidência de rejeição ao transplante (13).

Dentre as dezenove patologias - todas consideradas onco-hematológicas - constatadas nos pacientes do $\mathrm{HAJ}$, as mais freqüentes em ordem decrescente foram MM, LMA, LNH, LMC e LH. De acordo com Cottler-Fox et al. (14), o TMO autólogo tem sido um procedimento de grande valia na luta contra o câncer, pois possibilita o tratamento das doenças onco-hematológicas com grandes doses de quimioterápicos e, conseqüentemente, melhora os índices de não-remissão e cura dessas doenças. Destinase à extração das células-tronco sanguíneas do paciente antes da quimioterapia e à subseqüente conservação por meio de técnicas de criopreservação. Após o período de quimioterapia em altas doses, as células são descongeladas e reinfundidas no paciente por via intravenosa. Como não sofreram a ação dos quimioterápicos, essas células podem desenvolver-se normalmente e reconstituir o sistema hematopoiético, havendo uma diminuição do tempo de imunodepressão do paciente.

Os pacientes submetidos ao TMO autólogo formam um grupo heterogêneo no que diz respeito às doenças de base. O mieloma múltiplo perfaz um total de 22 casos, dentre os 106 pacientes analisados. De acordo com Burt et al. (11), o mieloma múltiplo é caracterizado pelo supercrescimento e pela disfunção das células plasmáticas da medula óssea. O crescimento das células plasmáticas interfere no crescimento dos glóbulos vermelhos, dos glóbulos brancos e das plaquetas. Conseqüentemente, a anemia, a suscetibilidade a infecções e tendências a sangramento são esperadas. À medida que as células crescem e se expandem na medula óssea, elas causam dor e destruição dos ossos. Essa ocorrência é mais comum por volta dos 60 anos de idade (com pico de incidência aos 70 anos); menos de 2\% dos casos ocorrem antes dos 40 anos. Há um discreto predomínio no sexo masculino e incidência duas vezes maior na população negra (15).

As leucemias são cânceres das células do sangue que habitualmente afetam os glóbulos brancos (leucócitos). A causa da maioria de seus tipos é desconhecida. Sua principal característica é o acúmulo de células jovens (blásticas) atípicas na medula óssea que passam a substituir as células sangüíneas normais. A leucemia mielóide aguda, assim como o mieloma múltiplo, apresenta um elevado índice entre os pacientes submetidos ao TMO no HAJ (21\%). Segundo o INCA (2004), há 10 mil pessoas com leucemia no Brasil, muitas delas dependendo de um TMO para sobreviver não só às leucemias, que afetam a maioria dos pacientes, mas também é uma provável chance de cura para portadores de outras setenta doenças. A leucemia mielóide aguda (LMA) representa cerca de $20 \%$ dos casos de leucemia. Relativamente bastante comum, são estimados aproximadamente 2 mil casos novos, anualmente, no estado de São Paulo (1). Em crianças, a leucemia linfóide aguda (LLA) é a mais comum, enquanto em adultos os tipos mais comuns são a LMA e a leucemia linfóide crônica (LLC), que ocorrem na mesma proporção nos sexos masculino e feminino (1). Convém ressaltar que há um maior risco em crianças previamente tratadas de outro tipo de câncer (1). Adicionalmente, os portadores de determinados distúrbios genéticos (por exemplo, da síndrome de Down e da síndrome de Fanconi) apresentam maior probabilidade de apresentar leucemia (1). A incidência é de 1 em 10 mil pessoas (1). Essas células leucêmicas acumulam-se na medula óssea, destruindo e substituindo as células produtoras de células sanguíneas normais. As células leucêmicas são liberadas na corrente sangüínea e transportadas até o fígado, baço, linfonodos, cérebro, rins e órgãos reprodutivos, onde continuam a crescer e a se dividir. Essas células podem não só irritar o revestimento do cérebro, causando meningite, mas também causar anemia, insuficiência hepática e renal e lesões de outros órgãos $(16,17)$.

Cabe ressaltar que, para um TMO bemsucedido, dois fatores são imprescindíveis: uma indicação precisa e um planejamento estratégico rigoroso. No HAJ, a equipe responsável pelos transplantes tem se aprimorado constantemente, graças à experiência advinda do número crescente desses procedimentos executados a cada ano que passa.

\section{Conclusão}

Ao final deste estudo, vários dados se evidenciaram, tais como: (a) o TMO é uma modalidade terapêutica destinada a pacientes de mau prognóstico; 
(b) a idade média dos transplantados do HAJ, no período enfocado, foi de 29,5, o que concorda com a revisão de literatura feita no início deste trabalho; (c) há um predomínio dos pacientes do sexo masculino; (d) MM, LMA, LNH, LMC e LH foram estatisticamente as doenças de base de maior incidência; (e) dentre os tipos de transplante, há um equilíbrio nos autólogos; (f) no que concerne à principal fonte celular, destacam-se as células-tronco do sangue periférico.

Com este, observa-se que no período de 2000 a 2004 no Hospital Araújo Jorge, o TMO apresentou um crescimento significativo, tornando esta unidade um centro de referência no que diz respeito ao transplante de medula óssea em Goiás.

\section{Referências}

1. Castro Jr CG, Gregianin LJ, Brunetto AL. Análise clínica e epidemiológica do transplante de medula óssea em um serviço de oncologia pediátrica. Jornal de Pediatria. 2003; 79(5):413-422.

2. Lorenzi TF. Manual de hematologia: propedêutica e clínica. $2^{\text {a }}$ ed. Rio de Janeiro: Medsi; 1999.

3. Anjos AR, Silva MA, Borelli P. Matriz extracelular e leucemia. Revista Brasileira de Hematologia e Hemoterapia. 2000; 22(3):404-412.

4. Abbas AK, Lichtman AH, Pober JS. Imunologia celular \& molecular. $3^{\mathrm{a}}$ ed. Rio de Janeiro: Revinter; 2000 .

5. Pallotta R, Ramos E, Ribeiro MR. Metodologia diagnóstica e tratamento da recaída após transplante de medula óssea em paciente com leucemia promielocítica aguda. Revista Brasileira de Hematologia e Hemoterapia. 2000; 22(3):414418.

6. Dulley FL. Transplante de medula óssea. Hematologia e Hemoterapia. 1996; 1(2):13-19.

7. Castro Jr CG, Gregianin LJ, Brunetto AL. Transplante de medula óssea e transplante de sangue de cordão umbilical em pediatria. Jornal de Pediatria. 2001; 77(5):345-360.
8. Azevedo W, Ribeiro MCC. Fontes de célulastronco hematopoéticas para transplantes. Revista Medicina de Ribeirão Preto. 2000; 33(4):381-389.

9. Associação Brasileira de Linfomas e Leucemia. Transplante de medula óssea [homepage on of Internet]. FALTA LOCAL: ABRALE; 2004. [atualizado 2006; citado 2006 jun 24]. Disponível em: URL: http://www.abrale.org.br

10. Anelli A, Galdenha AP, Gimenes DL. Revisão: Transplante de Medula Óssea. Acta Oncol Bras. 1997; 17(3):109-116.

11. Burt KR, Deeg HJ, Lonthian ST, Santos GW. Bone marrow transplantation. Texas (USA): Landes Bioscience; 1998.

12. Combs MR, Drew MJ, Goodnough LT, Grossman BJ, Harris T, Heddle N. American Association of Blood Banks: Technical Manual. 14 ${ }^{\text {th }}$ ed. USA; 2003.

13. Schmitz N, Barrett J. Optimizing engraftmentsource and dose of stem cells. Seminars in Hematology. 2002; 39(1):3-14.

14. Cottler-Fox MH, Lapidot T, Petit I, Kollet O, Dipersio JF, Link D, Devine S. Stem cell mobilization. Hematology. Jan. 2003; p. 419-437.

15. INCA/MS: Instituto Nacional de Câncer. Transplante de medula óssea/Ministério da Saúde [homepage on the Internet]. Rio de Janeiro: 2004 [atualizado 2006; citado 2006 jun 28]. Disponível em: URL: http://www.inca.org.br

16. Bonfim C, Pasquini R. Serviço de transplante de medula óssea - Hospital das Clínicas de Curitiba; 2002. Comunicação pessoal.

17. Voltarelli JC. Transplante de células-tronco hematopoéticas no diabete melito do tipo I. Revista Brasileira de Hematologia e Hemoterapia. 2004; 26(1):43-45.

Recebido em/Received in: July 03, 2006 Aceito em/Accepted in: August 29, 2006 